\title{
Acceptability and Feasibility of Postpartum Intra Uterine Contraceptive Device Insertion in Bangabandhu Sheikh Mujib Medical University, Dhaka, Bangladesh.
}

\author{
Nahar $\mathrm{KN}^{1}$, Fatima $\mathrm{P}^{2}$, Dewan $\mathrm{F}^{3}$, Yasmin $\mathrm{A}^{4}$, ${ }^{*}$ Laila $\mathrm{TR}^{5}$, Begum $\mathrm{N}^{6}$, Deeba $\mathrm{F}^{7}$, Chowdhury $\mathrm{S}^{8}$, Akhter $\mathrm{N}^{9}$
}

\begin{abstract}
Worldwide intra uterine contraceptive device (IUCD) is a reversible method of contraception. Postpartum IUCD insertion is labeled when IUCD is inserted within 10 minutes to 48 hours of expulsion of placenta. The objective of the study was to analyze the acceptability and feasibility of immediate postpartum intrauterine contraceptive device (PPIUCD) in a tertiary care hospital of Bangladesh. A cross sectional study was conducted among eligible postpartum women at Bangabandhu Sheikh Mujib Medical University (BSMMU), Dhaka Bangladesh. Counseling was done about the procedure of PPIUCD in details. After having the consent, Cu-T 380A was inserted in 343 women. The women were followed up at six weeks after delivery. A total number of 18190 women were counseled during antenatal period and at labor ward. A total number of 6441 were admitted for delivery. Among the
\end{abstract}

1. Dr. Khadiza Nurun Nahar, Associate Professor, Department of Obstetrics \& Gynaecology, Bangabandhu Sheikh Mujib Medical University (BSMMU)

2. Dr. Parveen Fatima, Professor \& Chairman, Department of Reproductive Endocrinology \& Infertility, BSMMU

3. Dr. Farhana Dewan, Professor \& Head Department of Obstetrics \& Gynaecology, Ibne Sina Medical College, Dhaka, Bangladesh.

4. Dr. Afroja Yesmin, National Project Manager, FIGO-PPIUD Project, Bangladesh.

5. *Dr. Tarafdar Runa Laila, Associate Professor, Department of Obstetrics \& Gynaecology, BSMMU. E-mail: trlaila@yahoo.com

6. Dr. Nurjahan Begum, Associate Professor, Department of Reproductive Endocrinology \& Infertility, BSMMU.

7. Dr. Farzana Deeba, Associate Professor, Department of Reproductive Endocrinology \& Infertility, BSMMU.

8. Dr. Shiuly Chowdhury, Associate Professor, Department of Obstetrics \& Gynaecology, BSMMU.

9. Dr. Nargis Akhter, Associate Professor, Department of Obstetric and Gynaecology, BSMMU

*For Correspondence admitted patients, 343 accepted this method. Forty nine percent of the acceptors belonged to the age group of $25-30$ years. Majority were from urban area and had studied up to secondary level. More women from the group who had undergone caesarean section accepted this method than the women who undergone vaginal delivery. Expulsion rate was $1.6 \%$ and removal rate 5.8\%. Most common reason for removal was irregular per vaginal bleeding. The immediate PPIUCD method appeared to be a safe and effective method of contraception.

Keywords: Postpartum intrauterine contraceptive device, PPIUCD, Postpartum

\section{INTRODUCTION}

Contraception means deliberate prevention of conception by any means be it drugs, technique or devices. In Bangladesh if we analyze use of different methods of contraception, oral contraceptive pill is highest in use. ${ }^{1}$ But the drawback is that it needs to be taken daily and missing dose can result to pregnancy. There are other methods that does not require daily intake and failure rate is also low. Among them there are depot injection, implant, intra uterine contraceptive device (IUCD) etc. IUCD is easily available in Bangladesh but less commonly used. ${ }^{2}$ It is a small T-shaped device placed in the uterus and its contraceptive action is 10-12 years. It can be removed at any time. Currently, in Bangladesh program is going on at the government and Non Governmental Organizational level on contraceptives including insertion of IUCD which is given as interval IUCD i.e. six weeks after delivery. But the user rate is relatively less due to lack of patient compliance. The reason may be the women need to contact with the family planning workers six weeks after child birth which is not always convenient for our women. From this point of view arises the concept of post partum IUCD (PPIUCD) where the IUCD is inserted into the uterus starting from 10 minute upto 48 hours after the birth of the baby. ${ }^{3}$

Multiple studies performed around the world have shown that adverse maternal, perinatal and infant outcomes are related to pregnancies spaced too closely. The risks are 
particularly high for women who become pregnant very soon after a previous pregnancy, miscarriage or abortion. ${ }^{4}$ The good news is that family planning enables women to achieve healthy intervals between births; potentially averting $25 \%$ to $40 \%$ of maternal deaths and reducing child mortality by an estimated $10 \%{ }^{5,6}$ As many as $62 \%$ of women globally have an unmet need for contraception in the postpartum period. ${ }^{7}$ So advice should be given on the use of a method which is long acting and can be adopted by the mothers immediately after childbirth. PPIUCD is a suitable method, free from risk, can be removed at any time. It can be given immediately after childbirth and can be used up to 12 years just like a permanent method relieving the worries and anxieties of future conception. American College of Obstetrics \& Gynaecology(ACOG) supports immediate postpartum long acting reversible contraceptive (LARC) insertion(i.e., intrauterine contraceptive device before hospital discharge) as a best practice, recognizing its role in preventing rapid repeat and unintended pregnancy. ${ }^{8}$ As PPIUCD insertion is done immediately after childbirth, so concern may arise regarding some complications like expulsion, infection etc.

From 2013, International Federation of Gynecology and Obstetrics (FIGO) has worked through the national societies globally to institutionalize the provision of postpartum IUD (PPIUD) services into routine maternity care. The project is being implemented in countries with relatively high fertility rates, unmet need for contraception and maternal mortality ratios. These include Tanzania, Kenya, India, Sri Lanka, Nepal and Bangladesh.

This project is implemented by Obstetrical and Gynecological Society in Bangladesh. PPIUCD insertion program is now going on in several health facilities of Bangladesh among which Bangabandhu Sheikh Mujib Medical University (BSMMU) is one of the centres. The aim of our study is to determine the acceptance rate of this method including analysis of acceptability and feasibility in terms of occurrence of expulsion or other complications.

\section{MATERIALS AND METHODS}

This cross sectional study was conducted from $1^{\text {st }}$ July 2015 to $30^{\text {th }}$ June 2018 in the department of Obstetrics and Gynaecology, BSMMU. Ethical clearance was taken from ethical society of the university. The patient were selected from those who got admitted to the obstetrics ward for delivery after fulfilling the inclusion and exclusion criteria. Inclusion criteria were woman who were counseled at antenatal clinic or in labor room for delivery per vaginally or by cesarean section and willing to participate in the study. Exclusion criteria were those unwilling to be included in the study, patient having anemia (hemoglobin $<10 \mathrm{gm} / \mathrm{dl}$ ), having PPH during delivery, history of rupture of membrane more than $>18$ hours, obstructed labor, patient having congenital malformation of uterus, history of pelvic infection, jaundiceand allergy to copper.

At first counseling of the patients were done by the counselor at the time of antenatal visit about the advantages and disadvantages of different types of contraceptives. Later, PPIUCD method specific counseling was done. Those who failed to have antenatal counseling were subjected to intranatal counseling. After obtaining written consent, IUCD was inserted immediately (within 10 minutes) following delivery of placenta in cases of vaginal delivery with utmost precaution and aseptically into the uterus. In cases of caesarean section IUCD was inserted directly into uterine fundus after delivery of placenta followed by closure of uterine incision.

Follow up was done at 6 week of puerperium in the outpatient department of obstetrics \&gynaecology, BSMMU. At that time symptoms and signs of any adverse effects like irregular per vaginal bleeding, excessive or foul smelling vaginal discharge, pain in the abdomen, dyspareunia were noted. Thread was also checked and if not found, ultrasonography of the lower abdomen was done. High vaginal swab for $\mathrm{C} / \mathrm{S}$ and urine RME and $\mathrm{C} / \mathrm{S}$ were done to those who complained of lower abdominal pain and excessive vaginal discharge. Women who came for follow up and want to remove the IUCD, reasons were meticulously noted in the questionnaires.All the relevant data were endorsed in the semi structured data collection sheets and analyzed using Statistical Package for Social Science (SPSS) software. Chi-squared Test $\left(\chi^{2}\right)$ was used to correlate the socio-demographic and obstetric characteristics of the parturient women. A p value of $<0.05$ was considered statistically significant.

\section{RESULTS}

From $1^{\text {st }}$ July 2015 to $30^{\text {th }}$ June 2018 , a total number of 18,190 pregnant mothers attending the antenatal clinic and labor ward were counseled and 2079 patients agreedfor insertion of a PPIUCD. 6441women were admitted for delivery at the hospital. Among the admitted patients, a total 343 patients ultimately accepted the PPIUCD as method of choice. Acceptance of PPIUCD among the agreed patients is $16.5 \%$. Acceptance rate among the delivered women is $5.3 \%$. 
Table I: Acceptance rate of PPIUCD (N=19,190)

\begin{tabular}{|l|c|}
\hline Total number of counseled women & 18,190 \\
\hline Total number of agreed women & 2079 \\
\hline Total number of delivered women at facility & 6441 \\
\hline $\begin{array}{l}\text { Total insertion of PPICUD } \\
\text { agreed women }\end{array}$ & 343 \\
\hline $\begin{array}{l}\text { \% of acceptance of PPIUCD among } \\
\text { delivered women }\end{array}$ & $5.3 \%$ \\
\hline
\end{tabular}

Forty nine percent of the acceptors belonged to the age group of $25-30$ years (Fig. 1). Table II shows the sociodemographic characteristics of the women. Eighty percent of the women who delivered in BSMMU are from urban area. The acceptance rate is slightly more for urban $(5.43 \%)$ than rural (4.88\%) women. Acceptance rate is a bit less among university educated women. Muslim and employed women accepted this method more than other religion and unemployed one. Women of middle socioeconomic group accepted the method more(8\%). Women having parity three accepted this method more.

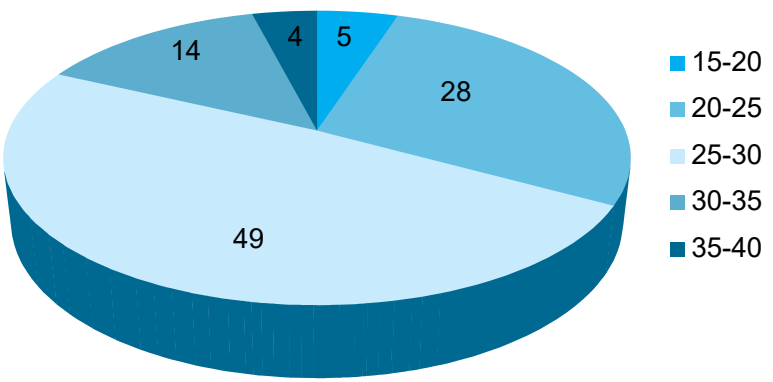

Figure 1 : Age distribution of patients (\%)

Table II: Socio demographic and obstetric characteristics of the parturient women ( $N=343)$

\begin{tabular}{|c|c|c|c|c|}
\hline Variables & $\begin{array}{l}\text { Accepted } \\
(\mathrm{N}=343) \\
\text { No. }(\%)\end{array}$ & $\begin{array}{c}\text { Declined } \\
(\mathrm{N}=6098) \\
\text { No. }(\%)\end{array}$ & $\begin{array}{c}\text { Total } \\
\mathrm{N}=6441 \\
\text { No. }(\%)\end{array}$ & $P$-value \\
\hline $\begin{array}{l}\text { Locality } \\
\text { Urban } \\
\text { Rural }\end{array}$ & $\begin{array}{c}280(5.43 \%) \\
63(4.88 \%)\end{array}$ & $\begin{array}{l}4872(94.56 \%) \\
1226(95.11 \%)\end{array}$ & $\begin{array}{l}5152(80 \%) \\
1289(20 \%)\end{array}$ & $0.433^{\text {ns }}$ \\
\hline $\begin{array}{l}\text { Education } \\
\text { No formal education } \\
\text { Primary } \\
\text { Secondary } \\
\text { College } \\
\text { University }\end{array}$ & $\begin{array}{c}6(4.76 \%) \\
91(5.16 \%) \\
118(5.84 \%) \\
96(5.2 \%) \\
32(4.6 \%)\end{array}$ & $\begin{array}{c}120(95.23 \%) \\
1670(94.83 \%) \\
1900(94.1 \%) \\
1744(94.8 \%) \\
696(95.4 \%)\end{array}$ & $\begin{array}{l}126(1.95 \%) \\
1761(27.34) \\
2018(31.33) \\
1840(28.56) \\
696(10.8 \%)\end{array}$ & $0.635^{\mathrm{ns}}$ \\
\hline $\begin{array}{l}\text { Occupation } \\
\text { Unemployed } \\
\text { Employed }\end{array}$ & $\begin{array}{l}279(5 \%) \\
65(9.6 \%)\end{array}$ & $\begin{array}{l}5489(95 \%) \\
609(90.3 \%)\end{array}$ & $\begin{array}{c}5768(89.5 \%) \\
674(10.5 \%)\end{array}$ & $<0.001^{*}$ \\
\hline $\begin{array}{l}\text { Socio Economic Status: } \\
\text { Upper class: } \\
\text { Middle class: } \\
\text { Lower class: }\end{array}$ & $\begin{array}{l}36(3.8 \%) \\
274(8 \%) \\
33(1.8 \%)\end{array}$ & $\begin{array}{c}905(96.1 \%) \\
3125(92 \%) \\
2068(98.4 \%)\end{array}$ & $\begin{array}{l}941(14.6 \%) \\
3399(52.8 \%) \\
2101(32.6 \%) \\
\end{array}$ & $<0.001^{*}$ \\
\hline $\begin{array}{l}\text { Religion: } \\
\text { Muslim: } \\
\text { Hindu } \\
\text { Christian }\end{array}$ & $\begin{array}{c}317(5.7 \%) \\
21(2.6 \%) \\
1(1.6 \%)\end{array}$ & $\begin{array}{c}5243(92.3 \%) \\
797(97.4 \%) \\
62(98.4 \%)\end{array}$ & $\begin{array}{c}5560(86.3 \%) \\
818(12.7 \%) \\
63(.97 \%)\end{array}$ & $<0.001^{*}$ \\
\hline $\begin{array}{l}\text { Parity: } \\
\text { Primi: } \\
2 \text { pregnancies } \\
3 \text { pregnancies }\end{array}$ & $\begin{array}{c}54(2.6 \%) \\
101(3.9 \%) \\
188(10.1 \%)\end{array}$ & $\begin{array}{l}2034(97.4 \%) \\
2494(96.1 \%) \\
1758(89.9 \%)\end{array}$ & $\begin{array}{l}2088(32.4 \%) \\
2595(40.2 \%) \\
1758(27.3 \%)\end{array}$ & $<0.001^{*}$ \\
\hline
\end{tabular}

Figures in the parentheses indicate corresponding percentage;

Chi-squared Test $\left(\chi^{2}\right)$ was done to analyze the data, ${ }^{*}$ significant, ns= not significant 
In this study women who had Lower segment caesarean section(LSCS) accepted PPIUCD more than who had vaginal delivery (VD). Out of 343 PPIUCD acceptors, 300 insertion was done during LSCS and 43 after VD. Out of 343 patients, 308 (89.8\%) patients reported for follow-up. Out of these, face to face follow-up was done in $264(86 \%)$ patients and phone follow-up was done in $44(14 \%)$ patients (table III).

Table III: Acceptance of PPIUCD in relation to mode of delivery $(\mathrm{N}=343)$

\begin{tabular}{|l|c|c|}
\hline Mode of delivery & Number & Percentage \\
\hline LSCS & 300 & 87.46 \\
\hline Vaginal delivery & 43 & 12.54 \\
\hline Returned follow up & 308 & $89.8 \%$ \\
\hline Face to face follow-up (N=308) & 264 & $86 \%$ \\
\hline Follow-up over telephone $(\mathrm{N}=308)$ & 44 & $14 \%$ \\
\hline
\end{tabular}

Among the follow-up patients, $20(6.5 \%)$ patients complained of irregular per vaginal bleeding, $12(3.9 \%)$ patients had lower abdominal pain, $8(2.6 \%)$ had excessive whitish per vaginal discharge. Upon vaginal inspection, $\mathrm{Cu}-\mathrm{T}$ thread was identified in 116 patients but could not be seen in 148 patients. In those where threads were not found were advised for ultrasonography of lower abdomen which showed that in five patients it has been expelled out. So the expulsion rate is $1.6 \%$ (table IV).

\section{Table IV: Complications or complaints among recipients of PPIUCD at six weeks $(\mathrm{N}=308)$}

\begin{tabular}{|l|c|c|}
\hline Complications/complaints & Number & Percentage \\
\hline Irregular bleeding & 20 & $5.8 \%$ \\
\hline Missing thread & 143 & 41.69 \\
\hline Infection & 0 & 0 \\
\hline Expulsion & 5 & 1.46 \\
\hline Uterine perforation & 0 & 0 \\
\hline Pain abdomen & 12 & 3.5 \\
\hline Excessive whitish per vaginal discharge & 8 & 2.3 \\
\hline
\end{tabular}

Table V: Reasons for removal of PPIUCD (N=20)

\begin{tabular}{|l|c|c|}
\hline Cause & Number & Percentage \\
\hline Irregular per vaginal bleeding & 10 & $50 \%$ \\
\hline Pressure from family & 5 & $25 \%$ \\
\hline $\begin{array}{l}\text { Pain abdomen, vaginal discharge, } \\
\text { dyspareunia }\end{array}$ & 2 & $10 \%$ \\
\hline Desire to conceive & 3 & $15 \%$ \\
\hline
\end{tabular}

Removal of IUCD was done in twenty (5.8\%) patients. Most common reason $(50 \%)$ was irregular per vaginal bleeding for long time. Other reasons were dislike by husband or mother-in-law, persistent lower abdominal pain, dyspareunia, profuse vaginal discharge and desire to conceive again (table IV).

Patients who complained of lower abdominal pain, excessive per vaginal discharge, irregular per vaginal bleeding were advised culture sensitivity of high vaginal swab but none of them revealed any bacterial growth. No perforation was found among the patients who returned for follow-up.

\section{DISCUSSION}

Women are highly motivated in postpartum period to initiate contraception. At this time they come in contact with health professionals and can be easily counseled. The total number of delivered women in BSMMU during the study period was 6441 among which 343 patients adopted PPIUCD method. So the acceptance rate among delivered patients is $5.3 \%$. Jairajet al. conducted a study in Telengana, India and got $19.7 \%$ acceptance rate. ${ }^{9}$ Kanhereet al. in their study conducted in Madhya Pradesh, India found 36\% acceptance rate. ${ }^{10}$ Mohamed et al. had similar study conducted in Assiut University, Egypt and there the acceptance rate was $28.9 \%{ }^{11}$ Compared to those above mentioned studies, acceptance rate in our study is low. Possible cause may be this immediate postpartal insertion method is a new one in our country. Patientshave got various misconceptions and fear about the method. Reasons related to the facility could be that BSMMU is a tertiary care hospital and most of the patients comes with complications related to delivery and also the facility has limited number of bed, so all the patients who were counseled in the ante natal clinic could not be admitted here during their delivery time. So, 
small percentage of counseled women had PPIUCD insertion.

The PPIUCD insertion rate is more among urban women (5.4\%) and in employed group (9.6\%) which is similar to the findings of Jairaj et al. Study of Sangeeta et al found acceptance is more in middle class family(39\%), patient whose educational status is up to secondary level (23.3\%), in primipara $(5.9 \%)$ and after LSCS $(43.9 \%)^{9}$.In our study, acceptance is more in middle class family $(8 \%)$, completion of secondary school (5.9\%),after three pregnancy (10\%) and following LSCS (5.7\%). Mohamed et al. found that acceptance is more in lower socioeconomic group,mostly grand multipara and more than $45 \%$ had got no formal education. ${ }^{11}$

In our study, acceptance of this method is more after LSCS $(87.46 \%)$ than vaginal delivery(12.54\%). This is similar to observation by Doley et al.(LSCS-77.07\%, VD-22.93\%) and Gautam et al(LSCS$36.09 \%, \mathrm{VD}-11.33 \%){ }^{12,13}$ The reason may be the patients want a long acting method after LSCS and majority of the acceptors underwent LSCS.

Loss of follow up is a common feature in all the studies. It was $58 \%$ in a study done by Nayak et al., $40 \%$ by Verma et al. but in our study it is less than $10.2 \%{ }^{14,15}$ Anita Makins et al. have studied in six countries at a time (Bangladesh, India, Nepal, Srilanka, Tanzania, Kenya)and found the follow up rate $52 \% .{ }^{16}$ Of them $49 \%$ were followed up face to face and $51 \%$ over telephone ${ }^{16}$. Though the follow up rate is high in our study but it is not due to either any complaints or complications. Reason of good follow up may be majority of acceptors $(87.46 \%)$ had LUCS and had to come for their post surgical follow up.

In our study regarding the complaints, therewere irregular per vaginal bleeding in twenty patients (6.5\%), lower abdominal pain in twelve patients (3.9\%), and excessivewhitish vaginal discharge in eight patients (2.6\%). There were no cases of PID. Jairaj et al. in her study has shown that $17.15 \%$ of her patients developed menstrual irregularity and lower abdominal pain. ${ }^{9}$ Kanhereet al observed that $8 \%$ of her patients developed lower abdominal pain and $6 \%$ menstrual irregularity. ${ }^{10}$ Kappa et al. had done systematic review of 15 articles on PPIUCD, they did not find any increase in risk of complications. ${ }^{17}$ No perforations were recorded in our study. This is to be expected as the immediate postpartum uterus differs greatly from the non pregnant uterus, which is at known risk of perforation during interval insertion (1-7\%) ${ }^{18}$ The large thick wall of the immediate postpartum uterus makes perforation highly unlikely.

Regarding the expulsion of the device in our study, it is very minimum only $1.6 \%$. But Mishra et al. found it to be $6.4 \%$, Goswamiet al. found it $22 \% .{ }^{19}, 20$ Studies done in six countries shows that the expulsion rate is $1.2 \%$ in Tanzania and $4.3 \%$ in Kenya. ${ }^{16}$ The risk of expulsion depends on timing, technique and expertise of the care provider. ${ }^{21}$ Immediate postpartum insertion (within 10 minutes) is associated with a lower risk of expulsion than early postpartum insertion (up to 48 hours). ${ }^{3}$ In our study twenty patients $(5.8 \%)$ voluntarily removed their device. The most common reason (50\%) for removal was bleeding followed by pressure from family $(25 \%) ; 10 \%$ had removal due to persistent lower abdominal pain, dyspareunia and profuse vaginal discharge, 15\% patients removed their device for future conception. Doley et al. found bleeding (42.11\%) and pressure fromfamily $(17.54 \%)$ to be the most common reasons for removal. ${ }^{12}$ Similar observationwas by Mishra et al. where bleeding $(32.56 \%)$ was the most common cause for removal. ${ }^{19}$ Whereas in a study by Goswami et al. the main reason for IUCD removal was pressure from husband and other family members. ${ }^{20}$

\section{Limitations and challenges}

Study was done at tertiary care hospital, which is in urban area, so the study populations are urban one. As this hospital has less bed, in proportion to outdoor patients, we could not admit all the agreed pregnant patients for PPIUCD during delivery. Some agreed patients had todeliver in other hospitals or at home andfailed to take PPIUCD method. So, number of insertion of PPIUCD isless in proportion to the agreed patients.

\section{CONCLUSION}

Insertion of IUCD in immediate postpartum period is an effective, safe and convenient contraceptive intervention in both caesarean and vaginal deliveries. The expulsion and complications are also less. The retention rate of IUCD is also good. But the acceptance rate is low. If health education, health promotion activities and counseling to family members including spouse and mother-in-laware vigorously done, 
acceptance may increase. Some misconception and fear of the patients about IUCD should be removed by proper counseling. Strategies to improve the insertion of PPIUCD, Government can take role in improving awareness about this method through different media sources. Antenatal counseling for family planning including PPIUCD andInstitutional delivery rate should be increased, so that PPIUCD and other family planning method can be given. Neonatal health services should be increased, so that perinatal mortality decreases and mothers can seek family planning methods with out worry. Female empowerment should be encouraged which will increase their decision making power about limitation of family. It is also important to train up the doctors, midwifes and other health care providers about the knowledge and skills of insertion of PPIUCD and follow up. This will further increase the rate of PPIUCD insertion and decrease the rate of expulsion. Follow up of the patients shouldalso be increased, so that more information about the complications and safety can be collected.

\section{REFERENCES}

1. Hubbard R, Goldstein S, Parveen S et al. Modern Contraceptive Options in Bangladesh. 26 th February, 2017.Available:

2. https://www.thedailystar.net , Health

2. Hossain A. IUD use in Bangladesh: The paradox of need, demand and supply continuum. British Medical Journal 2015;5 suppl 1.

3. Kapp $\mathrm{N}$ and Curtis KM. Intrauterine device insertion during the postpartum period: A systematic review. Contraception 2009; 80(4):327-336.

4. Post M. 2009.HTSP 101: Everything You Want to Know about Healthy Timing and Spacing of pregnancy. Extending Service Delivery Project: Washington,D.C.

5. Campbell MR and Graham WJ.Strategies for reducing maternal mortality: Getting on what works.Lancet 2006; 368(9543):1284-1299.

6. Cleland J, Bernstein S, Ezeh A, Faundes A, Glasier A and Innis J. Family planning: The unfinished agenda. Lancet2006; 368(9549):1810-1827.
7. Rossier C, Bradley SE, Ross J, Winfrey W. Reassessing unmet need for family planning in the postpartum period. Stud FamPlann 2015;46:355-67.

8. Committee on Practice Bulletins - Gynecology L-ARCWG. Practice Bulletin No. 186: long-acting reversible contraception: implants and intrauterine devices. ObstetGynecol 2017;130:e251-69.

9. Jairaj S, Dayyala S. A Cross Sectional Study on Acceptability and Safety of IUCD among Postpartum Mothers at Tertiary Care Hospital, Telengana. Journal of Clinical and Diagnostic Reasearch 2016 Jan; vol-10(1):LC01-LC04.

10. Kanhere AV, Pateriya P, Jain M. Acceptability and feasibility of immediate postpartum IUCD insertion in a tertiary care centre in Central India. Int J Reprod ContraceptObstetGynecol 2015 Feb; 4(1):179-184.

11. Mohamed SA, Kamel MA, Shaaban OM, Salem HT. Acceptability for the use of postpartum intrauterine contraceptive devices: Assiut experience. Med PrincPract. 2003 Jul-Sep;12(3):170-75.

12. Doley R, Pegu B. A retrospective study on acceptability and complications of PPIUCD insertion. J. Evolution Med. Dent. Sci./eISSN -2278 -4802, pISSN-2278-4748/vol.05/Issue31/Apr.18,2016.

13. Gautam R, Arya KN, Kharakwal S, Singh S, Trivedi M. Over view of immediate PPIUCD application in Bundelk hand region. J Evol Med Dent Sci 2014; 3(36):9518-26.

14. Nayak AK, Hota T. Hospital based -study regarding acceptance of PPIUCD as postpartum family planning method and its complications in a tertiary hospital. Indian J PerinatolReprod Biol. 2015;5(1):22-25.

15. Verma A, Sinha AR. Study of postpartum IUCD Insertions in Tertiary Health care Centre in Bihar. Indian J PerinatolReproduct Biol. 2104;4:8-10.

16. Makins A, Taghinejadi N, Sethi M, Machiyama K, Munganyizi P, Odongo E, et al. FIGO postpartum intrauterine device initiative: Complication rates across six countries. Int J Gynecol Obstet. 2018; 143(Suppl. 1): 20-27

17. Kappa A, Curtis KM. Intrauterine device insertion during the postpartum period: a sustematic review. Contraception. 2009; 80:327-36. 
18. Shukla M, Qureshi S, Chandrawati. Post-placental intrauterine device insertion - A five year experience at a tertiary care centre in north India. Indian J Med Res.2012 Sep; 136(30):432-435.

19. Mishra S. Evaluation of Safety, Efficacy and Expulsion of Post- Placental and Intra-cesarean Insertion of Intrauterine Contraceptive Devices (PPIUCD). J ObstetGynaecol India. 2014; 64(5):337-43.
20. Goswami G, Yadav K, Patel A. A Prospective Study to evaluate Safety, Efficacy and Expulsion Rate of Post Placental Insertion of Intra Uterine Devices (PPIUCD). Journal of Evolution of Medical and Dental Sciences. 2015;4(56):9770-74.

21. Chi IC, Wilkens L, Rogers S. Expulsions in immediate postpartum insertions of Lippes Loop D and Copper T IUDs and their counterpart Delta devices - An epidemiological analysis. Contraception. 1985;32(2):119-134. 